\title{
Lazer Kontrollü Tesviye Makinelerinin İş Derinliklerinin Belirlenmesi
}

\section{Hüseyin Nail AKGÜL $L^{* 1}$}

\section{${ }^{1}$ Aydın Adnan Menderes Üniversitesi Köşk Meslek Yüksek Okulu, Aydın}

Öz: Bir tarım işletmesinde karlılı̆ı̆n artırılması için işletmede gereksinim duyulan traktörler ve lazer kontrollü tesviye makinelerinin (LKTM) işletme özelliklerine uygun seçilmesi ve ekonomik olarak kullanılması için operatörlerin tecrübeli olması gerekmektedir. Tecrübe ise deneme-yanılma yöntemi ile veya eğitimle kazanılabilmektedir. Bu çalışmada operatörlerin eğitiminde kullanılacak abakların hazırlanması amaçlanmıştır. Dolayısıyla, dört farklı iş genişliğindeki LKTM $(3.5,4,5$ ve $6 \mathrm{~m})$ ile dört farklı traktör gücü $(85,95,140$ ve 160 BG) seçilmiştir. Bu LKTM ve traktör kombinasyonlarına uygun olarak güç gereksinimleri belirlenmiştir. Güç gereksinimlerine göre çalışabilecekleri maksimum iş derinlikleri saptanmıştır. Araştırma sonucuna göre; iş genişlikleri (LKTM) ve hız artıkça ihtiyaç duyulan traktör gücünde de artış görülmektedir. Aynı iş genişliğine sahip LKTM ile traktör kombinasyonunda, traktör gücü ve hızı artıkça iş derinliğinde de artış gözlemlenmiştir. Bu kapsamda LKTM'sini kullanan operatörler, hazırlanacak abaklar yardımıyla eğitilmelidir. Söz konusu çalışmada geliştirilen abaklar, tarla koşullarında denenmelidir. Elde edilen veriler göstermiştir ki, ülkemizde satılan farklı traktör güçleri ve farklı iş genişliğindeki LKTM kombinasyonlarına göre güç isteklerinin belirlenmesi ile çalışabilecekleri maksimum iş derinliklerinin hesaplanması gerekmektedir.

Anahtar Kelimeler: traktör, arazi, tarım, modelleme, iş genişliği

\section{Determination of Work Depth of Laser Controlled Leveling Machines}

\begin{abstract}
In order to increase profitability in an agricultural enterprise, operators must be experienced in order to select the tractors and laser-controlled leveling machines (LKTM) required in the enterprise in accordance with the operating characteristics and to use them economically. Experience can be gained by trial-and-error method or by training. In this study, it is aimed to prepare abacts to be used in training of operators. Therefore, four different working widths $\operatorname{LKTM}(3.5,4,5$ and $6 \mathrm{~m})$ and four different tractor power (85, 95, 140 and $160 \mathrm{HP}$ ) were chosen. Power requirements are determined in accordance with these LKTM and tractor combinations. Maximum working depths have been determined for working according to power requirements. According to results of the research, as work widths (LKTM) and speed increase, tractor power needed increases as well. In the combination of LKTM and tractor with the same working width, an increase in the working depth was observed as the tractor power and speed increased. In this context, operators using LKTM should be trained with the help of abacts to be prepared. Plows developed in the study should be tried in field conditions. The data obtained showed that it is necessary to calculate the maximum depths of work that can work by determining the power demands according to the different tractor powers sold in our country and LKTM combinations of different working widths.
\end{abstract}

Keywords: tractor, land, agricultural, modelling, work width

\section{GiRiş}

Teknolojilerdeki gelişmelere paralel olarak tarımsal uygulamalarda gelişmektedir. Gelişen tarımsal uygulamalar çiftçilere kolaylık sağlamaktadır. Çiftçilerin talepleri ve araştırmalar sonucunda tarım makineleri üreten firmalarda, tarımsal alet ve makinelerini geliştirmektedirler.

Tarımsal faaliyetlerde ekim öncesi tarlanın hazırlığı önemlidir (Ravindra ve ark., 2017). Bu kapsamda iyi bir hazırlanmış tarlada çukur veya tümsek oluşması, su birikmesi vb. durumlar istenmemektedir. Çiftçiler bu durumları engellemek için ekim öncesi hazırlıklarda tesviye küreklerini kullanabilirler. Tesviye küreklerinde çiftçinin tecrübesine göre tarla düzeltilmektedir. Ancak tarlanın hangi tarafında kot yüksekliği olduğu bilinmesi zordur. Çiftçiler bunu yıl içinde gözlemleyerek tecrübe edinirler ve bir sonraki sezonda uygulayabilirler. Ne kadar tecrübeli olsalar dahi teknolojik makinelerden daha iyi düzeltme yapamamaktadırlar.

Lazer kontrollü tesviye makinesi (LKTM) çiftçilerin ekim öncesi tarlalarını hazırlamakta büyük kolaylık sağlamaktadır.
LKTM sistemini oluşturan unsurlar Şekil 1'de gösterilmektedir (Tepeli ve Sarıtaş, 2005);

- Lazer ışın vericisi

- Lazer alıcısı

- Kontrol kutusu

- Ara kablolar

- Hidrolik aksam

Lazer ışın vericisi tarlanın uygun bir yerine konulabilir, buradan 360 derece dönerek paralel veya belli bir eğimde lazer ışı̆̆ı gönderebilmektedir. Lazer ışın alıcısı ise gelen lazer ışığını algılayarak kontrol kutusuna iletebilmektedir. Kontrol kutusunda ise tarlanın durumuna göre kazı veya dolgu yapmak üzere tesviye küreği aşağı yukarı hareket ettirilmektedir (Anonim, 2020).

Sorumlu Yazar: hakgul@adu.edu.tr

Geliş Tarihi: 1 Mayıs 2020

Kabul Tarihi: 27 Mayıs 2020 

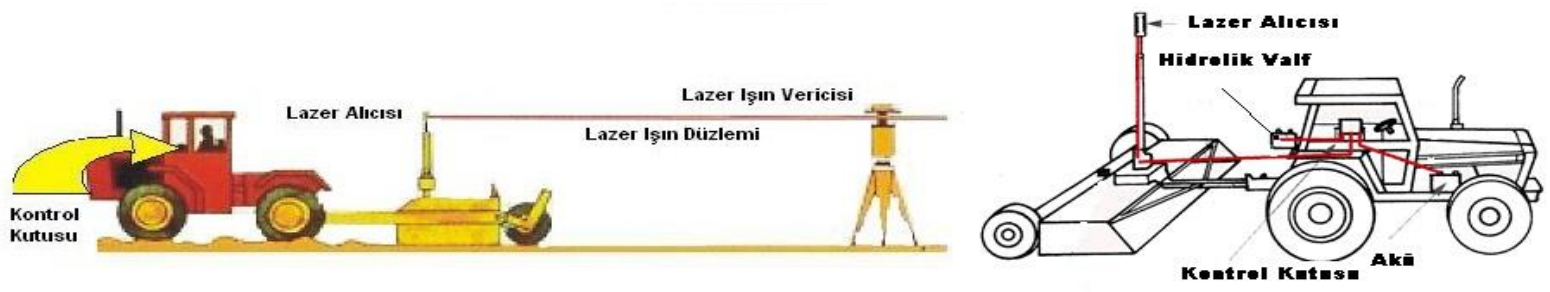

Şekil 1. Lazerli tesviye sistemi

LKTM ile arazinin tesviyesi, yeni bir kaynak koruma teknolojisidir. Kullanılan girdilerin verimliliğini artırarak üretimi artırabilmektedir (Kumaran ve Rathinakumari, 2016). LKTM avantajları (Rickman, 2002);

- Zirai mekanizasyon daha kolay yapılabilir

- Yabancı otlarla daha etkin mücadele yapılabilir

- Tohum, gübre, ilaç ve yakıt gideri azaltılabilir

- Sulama suyu \%20-30 daha az kullanılabilir

- $\quad \% 10-20$ arasında daha yüksek verim elde edilebilir

- Işlenebilir alan yaklaşık \%3-5 artabilir (Jat ve ark., 2006).

- Üretim maliyeti pirinç, buğday, soya pamuk ve mısırda \%6.3-15.4 azaltılabilir (Jat ve ark., 2006).

LKTM avantajlarının yanında dezavantajları da bulunmaktadır. Bunlar (Jat ve ark., 2006);

- Yüksek çeki gücü gerektiren traktörlere ihtiyaç duyulabilir.

- Satın alma maliyeti yüksektir.

- Operatörün tecrübesi

- Tarla boyutunun büyüklüğü ve şekli (Küçük ölçekli alanlarda ve düzensiz şekillerde).

$\mathrm{Bu}$ dezavantajlarına rağmen LKTM ile yapılan arazi tesviyeleri, çiftçiler arasında giderek daha popüler hale gelmektedir (Rajput, 2016).

Tesviye işlemine başlamadan önce tarla tesviye kodunun bulunması için her 20-50 metrede bir ölçüm alınabilir. Bu işlemle ilgili bir örnek Çizelge 1'de verilmiştir.

Çizelge 1. Tesviye kodu değerlerinin bulunması (cm)

\begin{tabular}{|c|c|c|c|c|}
\hline 15 & 6 & 11 & 20 & 1 \\
\hline 16 & 7 & 12 & 21 & 2 \\
\hline 17 & 8 & 3 & 22 & 3 \\
\hline 18 & 9 & 14 & 23 & 4 \\
\hline 19 & 10 & 15 & 24 & 5 \\
\hline
\end{tabular}

$305 / 25=12.2 \mathrm{~cm}$

Yapılan ölçümlerin toplamı 305, ölçüm yapılan sayı 25 bulunduğundan $305 / 25=12.2 \mathrm{~cm}$ tesviye kodu ortalaması bulunur. Bu değer bize kazı dolgu haritası için referans değerdir. Çizelge 1'de 12.2 değerin üstündeki sayılarda kazı, 12.2 değerinin altındaki sayılarda ise dolgu yapılacaktır. Buna göre hazırlanan kazı-dolgu haritası Çizelge 2'de verilmiştir.

Çizelge 2. Kazı-Dolgu haritası

\begin{tabular}{|c|c|c|c|c|}
\hline $\begin{array}{c}15-12.2 \\
\text { K2.8 }\end{array}$ & $\begin{array}{c}12.2-6 \\
\mathrm{D} 6.2\end{array}$ & $\begin{array}{c}12.2-11 \\
\mathrm{D} 1.2\end{array}$ & $\begin{array}{c}20-12.2 \\
\mathrm{~K} 7.8\end{array}$ & $\begin{array}{c}12.2-1 \\
\mathrm{D} 11.2\end{array}$ \\
\hline $16-12.2$ & $12.2-7$ & $12.2-12$ & $21-12.2$ & $12.2-2$ \\
$\mathrm{~K} 3.8$ & $\mathrm{D} 5.2$ & $\mathrm{D} 0.2$ & $\mathrm{~K} 8.8$ & $\mathrm{D} 10.2$ \\
\hline $17-12.2$ & $12.2-8$ & $12.2-3$ & $22-12.2$ & $12.2-3$ \\
$\mathrm{~K} 4.8$ & $\mathrm{D} 4.2$ & $\mathrm{D} 9.2$ & $\mathrm{~K} 9.8$ & $\mathrm{D} 9.2$ \\
\hline $18-12.2$ & $12.2-9$ & $14-12.2$ & $23-12.2$ & $12.2-4$ \\
$\mathrm{~K} 5.8$. & $\mathrm{D} 3.2$ & $\mathrm{~K} 1.8$ & $\mathrm{~K} 10.8$ & $\mathrm{D} 8.2$ \\
\hline $19-12.2$ & $12.2-10$ & $15-12.2$ & $24-12.2$ & $12.2-5$ \\
$\mathrm{~K} 6.8$. & $\mathrm{D} 2.2$ & $\mathrm{~K} 2.8$ & $\underline{\mathrm{K} 11.8}$ & $\mathrm{D} 7.2$ \\
\hline
\end{tabular}

Kazı-dolgu haritalarında kazının yapılacağı en büyük değer ve dolgunun yapılacağı en büyük değerler belirlenir. En büyük kazı yerinden en küçük dolgu yerine hareket edilerek tesviye işlemi yapılır. Böylelikle, birim zaman ve maliyetten tasarruf sağlanabilir.

LKTM satıcılarının kataloglarda belirtmiş olduğu, iş genişliğine göre çeki gücünü gerçekleştirecek traktör gücü gereksinimleri Çizelge 3'de belirtilmiştir (Anonim, 2010a).

Traktör güç gereksinimlerini firmalar kataloglarında belirtmelerine rağmen kazı-dolgu haritalarında LKTM ve traktör kombinasyonunda iş derinliği hakkında bir bilgi bulunmamaktadır. Operatörler tecrübeleri deneme-yanılma yöntemi ile belirleyebilmektedir. Bu yöntem hem pahalı hem de zaman gerektirmektedir. Firmalar operatörlere, LKTM tanıtılmasını ve arazi eğitimlerini vermektedirler. Ancak iş derinliği hakkında net bir eğitim vermemektedirler. $\mathrm{Bu}$ çalışma, tarım işletmesinde karlılığın artırılması için işletmede gereksinim duyulan traktör, LKTM işletme özelliklerine uygun seçilmesi ve ekonomik olarak kullanılması için operatörlerin eğitiminde kullanılacak iş derinlik abakların hazırlanması ile yukarıda belirtilen eksikliği gidermeyi amaçlamaktadır.

Çizelge 3. İş genişliklerine göre LKTM çekebilecek minimum traktör büyüklükleri

\begin{tabular}{lllll}
\hline İ̧̧ genişliği (m) & 3.5 & 4 & 5 & 6 \\
Traktör gücü (BG) & $85-120$ & $100-140$ & $120-180$ & $160-210$ \\
\hline
\end{tabular}




\section{MATERYAL VE YÖNTEM}

Farklı iş genişliğindeki LKTM güç büyüklüklerinin belirlenmesi için; New Holland traktörlerin farklı beygir güçlerindeki 4 modeli ile İlgi Tarım makinelerinin LKTM farklı iş genişliğindeki 4 model seçilmiştir. Bunlar (Anonim, 2010a; Anonim 2010b ve Anonim, 2010c);

- New Holland TD 85 D (85 BG)

- New Holland TD 95 D (95 BG)

- New Holland T 6060 ELITE (140 BG )

- New Holland T 6080 (160 BG)

- $\operatorname{LTSV} 35$ (3.5 m)

- $\operatorname{LTSV} 40(4 \mathrm{~m})$

- $\quad$ LTSV 50 (5 m)

- $\operatorname{LTSV} 60$ (6 m)

Farklı iş genişliğindeki LKTM güç büyüklüklerinin belirlenmesinde kullanılan matematiksel modelleme, "Meliorasyon Makinaları" (Erdoğan ve ark, 2003) kitabına göre yapılmıştır (Çizelge 4, Çizelge 5, Çizelge 6 ve Çizelge 7). Matematiksel modellemede kullanılan formüller aşağıda açıklanmıştır.

Çizelge 4. Yuvarlanma direnci katsayısı değerleri (f)

\begin{tabular}{|c|c|c|}
\hline \multirow{3}{*}{ Zemin Durumu } & \multicolumn{2}{|c|}{ Lastik tekerlekler } \\
\hline & Yüksek & Düşük \\
\hline & Basınçlı & Basınçlı \\
\hline Beton yol & 0.02 & 0.025 \\
\hline İyi tarla yolu & 0.05 & 0.035 \\
\hline Kuru, sertçe tınlı kil & $0.05-0.09$ & - \\
\hline Kuru, sertçe anız & $0.05-0.10$ & 0.04 \\
\hline Kuru, normal tarla toprağı & $0.07-0.12$ & - \\
\hline Nemli, sertçe anız & 0.12 & 0.80 \\
\hline Kuru, tınlı kum & $0.10-0.15$ & - \\
\hline Nemli, tınlı kum, anız & $0.12-0.17 *$ & 0.12 \\
\hline Çok nemli, kumlu tın, killi tın & $0.15-0.25$ & 0.15 \\
\hline Nemli, balçıklı kum & - & 0.20 \\
\hline $\begin{array}{l}\text { Islak killi tın, yapışkan tarla } \\
\text { toprağı }\end{array}$ & $0.20-0.35$ & 0.25 \\
\hline
\end{tabular}

*Bu hesaplamada yuvarlanma direnci katsayısı; nemli, tınlı kum, anız için 0.17 olarak alınmıştır.

Çizelge 5. Toprakların özgül kesme dirençleri (k)

\begin{tabular}{lc}
\hline Toprak grubu & Özgül kesme direnci $\left(\mathrm{daN} / \mathrm{cm}^{2}\right)$ \\
\hline Hafif topraklar & $0.5-0.7$ \\
Orta ağır topraklar & $0.8-1.1$ \\
Ağır topraklar & $1.2-1.7^{*}$
\end{tabular}

*Bu hesaplamada toprağın özgül kesilme direnci $1.7 \mathrm{daN} / \mathrm{cm}^{2}$ alınmıştır.
Çizelge 6. Toprak grupları ve özellikleri

AKGÜL HN

\begin{tabular}{|c|c|c|}
\hline \multicolumn{2}{|l|}{ Gruplar } & $\begin{array}{l}\text { İç sürtünme } \\
\text { katsayısı ( } \mu \mathrm{i})\end{array}$ \\
\hline \multicolumn{2}{|l|}{ Hafif (kumlu) topraklar } & $0.57-0.84$ \\
\hline \multicolumn{2}{|c|}{ Hafif -Orta ağır (humuslu) topraklar } & $0.70-0.90$ \\
\hline \multicolumn{2}{|c|}{ Orta ağır (kireçli) topraklar } & $0.78-1.00$ \\
\hline \multicolumn{2}{|c|}{ Orta ağır-ağır (tınlı) topraklar } & $0.90-1.20 *$ \\
\hline \multicolumn{2}{|l|}{ Ağır (killi) topraklar } & $1.10-2.15$ \\
\hline \multicolumn{3}{|c|}{$\begin{array}{l}\text { *Bu hesaplamada, toprağın iç sürtünme katsayısı, orta ağır-ağ } \\
\text { (tınlı) topraklar için } 1.20 \text { olarak alınmıştır. }\end{array}$} \\
\hline \multicolumn{3}{|c|}{ Çizelge 7. Bazı materyallerin ağırıkları $\left(\gamma_{\mathrm{k}}\right)$} \\
\hline Materyal & $\begin{array}{l}\text { Doğal haldeki } \\
\text { ağırlık } \\
\left(\mathrm{kg} / \mathrm{m}^{3}\right)\end{array}$ & $\begin{array}{l}\text { Kabarık } \\
\text { haldeki ağırlık } \\
\left(\mathrm{kg} / \mathrm{m}^{3}\right)\end{array}$ \\
\hline Kuru kil & 12.263 & 1090 \\
\hline Islak veya sıkışmış kil & 1777 & 12.233 \\
\hline Kuru toprak & 1659 & 12.227 \\
\hline Islak toprak & 1997 & 1599 \\
\hline $\begin{array}{l}\text { *Çakıllı veya kumlu } \\
\text { toprak }\end{array}$ & 1867 & 1564 \\
\hline Kuru çakıl & 1925 & 1718 \\
\hline Islak çakıl & 212.23 & 1896 \\
\hline Tın & 1596 & 12.227 \\
\hline Kırılmış tay ya da kaya & 1919-2322 & $1422-1728$ \\
\hline
\end{tabular}

*Kabarık toprağın birim hacim ağırlı̆̆ı, çakıllı veya kumlu toprak için $1600 \mathrm{~kg} / \mathrm{m}^{3}$ olarak alınmıştır.

Motor Gücü

$\mathrm{P}_{\mathrm{e}}=\frac{\mathrm{R}_{\text {top }} \cdot \mathrm{v} \cdot(1+\mathrm{p})}{360 \cdot \eta_{\mathrm{tr}}}$

$\mathrm{P}_{\mathrm{e}}$ : Küremede gerekli motor gücü $(\mathrm{kW})$

$\mathrm{R}_{\text {top }}$ : Toplam direnç (daN)

v: Küreme hızı $(\mathrm{km} / \mathrm{h})$

p: Patinaj oranı (0.15-0.25)

$\eta_{\text {tr: }}$ Transmisyon tesir derecesi

Patinaj oranı 0.15 ile 0.20 arasında değişmektedir. Bu hesaplamada Patinaj oranı "0.20" olarak alınmıştır.

Transmisyon tesir derecesi de 0.90 olarak alınmıştır.

Toplam Direnç Kuvveti

$\mathrm{R}_{\text {top }}=\mathrm{R}_{\mathrm{y}}+\mathrm{R}_{2}+\mathrm{R}_{3}+\mathrm{R}_{\mathrm{m}}$

$\mathrm{R}_{\text {top }}$ : Toplam direnç (daN)

$R_{y}$ : Yürüme direnci (daN)

$\mathrm{R}_{2}$ : Toprağın kesilme direnci (daN)

$\mathrm{R}_{3}$ : Toprağın küremeye karşı gösterdiği direnç (daN)

$\mathrm{R}_{\mathrm{m}}$ : Meyil direnci (daN)

Yürüme direnci

$\mathrm{R}_{\mathrm{y}}=\left(\mathrm{G}+\mathrm{G}_{\mathrm{t}}\right) \times \mathrm{f}$

$R_{y}$ : Yürüme direnci (daN)

G: Makinanın toplam ağırlığı (kg)

$\mathrm{G}_{\mathrm{t}}$ : Traktörün ağırlığı $(\mathrm{kg})$

f: Yuvarlanma direnci katsayısı (Nemli, tınlı kum, anız için 0.17) 


\section{Toprağın kesilme direnci}

$\mathrm{R}_{2}=\mathrm{k} \cdot \mathrm{b} \cdot \mathrm{h}$

$\mathrm{R}_{2}$ : Toprağın kesilme direnci (daN)

$\mathrm{b}$ : İ̧̧ genişliği $(\mathrm{cm})$

$\mathrm{h}$ : İs derinliği $(\mathrm{cm})$

k:Toprağın özgül kesilme direnci $\left(\mathrm{daN} / \mathrm{cm}^{2}\right)$

Toprağın küremeye karşı gösterdiği direnç

$\mathrm{R}_{3}=\mathrm{V} \cdot \mu_{\mathrm{i}} \cdot \gamma_{\mathrm{k}}$

$\mathrm{R}_{3}$ : Toprağın küremeye karşı gösterdiği direnç (daN)

$\mathrm{V}$ : Kürenen toprak hacmi $\left(\mathrm{m}^{3}\right)$

$\mu_{\mathrm{i}}$ : Toprağın iç sürtünme katsayısı

$\gamma_{\mathrm{k}}$ : Kabarık toprağın birim hacim ağırlığı $\left(\mathrm{kg} / \mathrm{m}^{3}\right)$

\section{Kürenen toprak hacmi}

$\mathrm{V}=\frac{\mathrm{k}_{1} \cdot \mathrm{b} \cdot \mathrm{h}^{2}}{2}$

$\mathrm{V}:$ Kürenen toprak hacmi $\left(\mathrm{m}^{3}\right)$

$\mathrm{k}_{1}$ :Katsayı

- Doğal nemli yapışkan topraklar için 1.3

- Yapışkan olmayan toprak için 0.8

b·h: Bıçak ölçüleri (m)

$\mathrm{b}$ : İş genişliği $(\mathrm{m})$

h: Kürek yüksekliği (m)

Bu çalışmada $k_{1}$ katsayısı, doğal nemli yapışkan topraklar için 1.3 olarak alınmıştır.
Meyil direnci

$\mathrm{R}_{\mathrm{m}}=\left(\mathrm{G}+\mathrm{G}_{\mathrm{t}}\right) \cdot \sin \alpha$

$\mathrm{R}_{\mathrm{m}}$ : Meyil direnci (daN)

$\mathrm{G}$ : Makinanın toplam ağırlığı $(\mathrm{kg})$

$\mathrm{G}_{\mathrm{t}}$ : Traktörün ağırlığı $(\mathrm{kg})$

$\alpha$ : Meyil derecesi

Bu çalışmada meyil derecesi " 0 " olarak alınmıştır.

Küremede gerekli motor gücünün belirlenmesinde 1, 2, 3, 4, 5, 6 ve 7 nolu eşitlikler kullanılarak, Excel 2013'de hesaplanmıştır. Bu veriler incelenerek LKTM ve traktör kombinasyonuna uygun iş derinlikleri çizelgesi oluşturulmuştur.

\section{BULGULAR VE TARTIŞMA}

Bu çalışmada yukarıda bahsedilen eşitlikler yardımı ile küreme için gerekli motor gücünün hesaplanmasında kullanılan Excel programı Şekil 2'de verilmiştir.

Farklı iş genişliğindeki LKTM ve farklı beygir gücündeki traktör kombinasyonlarının, farklı hızlarda çalışabileceği maksimum iş derinliği Çizelge $8^{\prime}$ de verilmiştir.

Çizelge 8 incelendiğinde;

\section{$1 \mathrm{~km} / \mathrm{h}$ hızda}

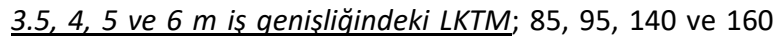
BG gücündeki traktörlerle $10 \mathrm{~cm}$ 'ye kadar iş derinliğinde kazıma işi yapabilmektedir.

\begin{tabular}{|c|c|c|c|c|c|c|c|c|c|c|}
\hline k1 & 1,3 & & & & & & & & & \\
\hline b & 3,5 & & & & & & & & & \\
\hline h & 0,85 & & & & & & & & & \\
\hline $\mathbf{V}$ & 1,644 & & & & & & & & & \\
\hline$\mu \mathbf{i}$ & 1,2 & & & & & & & & & \\
\hline$\gamma \mathbf{k}$ & 1600 & & & & & & & & & \\
\hline $\sin \alpha(0)$ & 0 & & & & & & & & & \\
\hline $\mathbf{k}$ & 1,7 & & & & & & & & & \\
\hline b & 350 & & & & & & & & & \\
\hline $\mathbf{f}$ & 0,17 & & & & & & & & & \\
\hline p & 0,2 & & & & & & & & & \\
\hline$\eta \operatorname{tr}$ & 0,9 & & & & & & & & & \\
\hline $\mathbf{R y}$ & 1357 & & & & & & & & & \\
\hline $\mathbf{R 2}$ & 595 & 1190 & 1785 & 2380 & 2975 & 3570 & 4165 & 4760 & 5355 & 5950 \\
\hline$(1+p)^{*} 1,36 / 360 * \eta t r$ & 0,005 & & & & & & & & & \\
\hline$V *(1+p) * 1,36 / 360 * \eta \operatorname{tr}$ & 0,015 & 0,01 & 0,015 & 0,02 & 0,025 & 0,03 & 0,035 & 0,04 & & \\
\hline $\mathbf{V}$ & 1 & 2 & 3 & 4 & 5 & 6 & 7 & 8 & & \\
\hline $\mathbf{h}$ & 1 & 2 & 3 & 4 & 5 & 6 & 7 & 8 & 9 & 10 \\
\hline $\operatorname{Pe}(\mathbf{B G})(\mathrm{V}=\mathbf{1})$ & 26 & 29 & 31 & 34 & 37 & 40 & 43 & 46 & 49 & 52 \\
\hline $\operatorname{Pe}(\mathbf{B G})(\mathrm{V}=\mathbf{2})$ & 51 & 57 & 63 & 69 & 75 & 81 & 87 & 93 & 99 & 105 \\
\hline $\operatorname{Pe}(\mathbf{B G})(\mathrm{V}=\mathbf{3})$ & 77 & 86 & 94 & 103 & 112 & 121 & 130 & 139 & 148 & 157 \\
\hline $\operatorname{Pe}(\mathbf{B G})(\mathrm{V}=\mathbf{4})$ & 102 & 114 & 126 & 138 & 150 & 162 & 174 & 185 & 197 & 209 \\
\hline $\operatorname{Pe}(\mathbf{B G})(\mathrm{V}=5)$ & 128 & 143 & 157 & 172 & 187 & 202 & 217 & 232 & 247 & 262 \\
\hline $\operatorname{Pe}(\mathbf{B G})(\mathrm{V}=6)$ & 153 & 171 & 189 & 207 & 225 & 242 & 260 & 278 & 296 & 314 \\
\hline $\operatorname{Pe}(\mathbf{B G})(\mathrm{V}=7)$ & 179 & 200 & 220 & 241 & 262 & 283 & 304 & 325 & 345 & 366 \\
\hline $\operatorname{Pe}(\mathbf{B G})(\mathrm{V}=\mathbf{8})$ & 204 & 228 & 252 & 276 & 299 & 323 & 347 & 371 & 395 & 418 \\
\hline
\end{tabular}

Şekil 2. Motor gücü hesaplanmasında kullanılan excel programı 
Çizelge 8. Farklı iş genişliğinde LKTM ve farklı beygir gücündeki traktör kombinasyonlarının, farklı hızlarda çalışabileceği maksimum iş derinliği.

\begin{tabular}{|c|c|c|c|c|}
\hline \multicolumn{5}{|c|}{$1 \mathrm{~km} / \mathrm{h}$} \\
\hline İş genişliği & $3.5 \mathrm{~m}$ & $4 m$ & $5 \mathrm{~m}$ & $6 \mathrm{~m}$ \\
\hline 85 BG & $10 \mathrm{~cm}$ & $10 \mathrm{~cm}$ & $10 \mathrm{~cm}$ & $1 \mathrm{~cm}$ \\
\hline 95 BG & $10 \mathrm{~cm}$ & $10 \mathrm{~cm}$ & $10 \mathrm{~cm}$ & $2 \mathrm{~cm}$ \\
\hline 140 BG & $10 \mathrm{~cm}$ & $10 \mathrm{~cm}$ & $10 \mathrm{~cm}$ & $7 \mathrm{~cm}$ \\
\hline 160 BG & $10 \mathrm{~cm}$ & $10 \mathrm{~cm}$ & $10 \mathrm{~cm}$ & $9 \mathrm{~cm}$ \\
\hline \multicolumn{5}{|l|}{$2 \mathrm{~km} / \mathrm{h}$} \\
\hline 85 BG & $7 \mathrm{~cm}$ & $5 \mathrm{~cm}$ & $3 \mathrm{~cm}$ & - \\
\hline 95 BG & $8 \mathrm{~cm}$ & $7 \mathrm{~cm}$ & $4 \mathrm{~cm}$ & - \\
\hline 140 BG & $10 \mathrm{~cm}$ & $10 \mathrm{~cm}$ & $9 \mathrm{~cm}$ & $2 \mathrm{~cm}$ \\
\hline 160 BG & $10 \mathrm{~cm}$ & $10 \mathrm{~cm}$ & $10 \mathrm{~cm}$ & $3 \mathrm{~cm}$ \\
\hline \multicolumn{5}{|l|}{$3 \mathrm{~km} / \mathrm{h}$} \\
\hline 85 BG & $2 \mathrm{~cm}$ & $1 \mathrm{~cm}$ & - & - \\
\hline 95 BG & $3 \mathrm{~cm}$ & $2 \mathrm{~cm}$ & - & - \\
\hline 140 BG & $8 \mathrm{~cm}$ & $6 \mathrm{~cm}$ & $4 \mathrm{~cm}$ & - \\
\hline $160 \mathrm{BG}$ & $10 \mathrm{~cm}$ & $8 \mathrm{~cm}$ & $5 \mathrm{~cm}$ & - \\
\hline \multicolumn{5}{|l|}{$4 \mathrm{~km} / \mathrm{h}$} \\
\hline 140 BG & $4 \mathrm{~cm}$ & $1 \mathrm{~cm}$ & - & - \\
\hline $160 \mathrm{BG}$ & $5 \mathrm{~cm}$ & $2 \mathrm{~cm}$ & $1 \mathrm{~cm}$ & - \\
\hline \multicolumn{5}{|l|}{$5 \mathrm{~km} / \mathrm{h}$} \\
\hline 140 BG & $2 \mathrm{~cm}$ & $1 \mathrm{~cm}$ & - & - \\
\hline $160 \mathrm{BG}$ & $3 \mathrm{~cm}$ & $2 \mathrm{~cm}$ & - & - \\
\hline \multicolumn{5}{|l|}{$6 \mathrm{~km} / \mathrm{h}$} \\
\hline $160 \mathrm{BG}$ & $1 \mathrm{~cm}$ & - & - & - \\
\hline
\end{tabular}

$2 \mathrm{~km} / \mathrm{h}$ hızda

$3.5 \mathrm{~m}$ iș genișliğinde LKTM; 85 BG gücündeki traktörlerle 7 $\mathrm{cm}$ kadar kazıma işi yapabilmektedir. 95 BG gücündeki traktörlerle $8 \mathrm{~cm}$ kadar kazıma işi yapabilmektedir. 140 ve 160 BG gücündeki traktörlerle 1'den 10 cm'ye kadar kazıma işi yapabilmektedir. $4 \mathrm{~m}$ iș genişliğinde LKTM; 85 BG gücündeki traktörlerle $5 \mathrm{~cm}$ kadar kazıma işi yapabilmektedir. 95 BG gücündeki traktörlerle $7 \mathrm{~cm}$ kadar kazıma işi yapabilmektedir. 140 ve 160 BG gücündeki traktörlerle 1'den $10 \quad \mathrm{~cm}^{\prime}$ ye kadar kazıma işi yapabilmektedir.

$5 \mathrm{~m}$ is genişliğinde LKTM; 85 BG gücündeki traktörle, $3 \mathrm{~cm}$ kadar kazıma işi yapabilmektedir. 95 BG gücündeki traktörlerle $4 \mathrm{~cm}$ kadar kazıma işi yapabilmektedir. 140 BG gücündeki traktörlerle $9 \mathrm{~cm}$ kadar kazıma işi yapabilmektedir. 160 BG gücündeki traktörlerle 1'den 10 $\mathrm{cm}^{\prime}$ ye kadar kazıma işi yapabilmektedir.

$6 \mathrm{~m}$ iș genişliğinde LKTM; 85 BG gücündeki traktörlerle 1 $\mathrm{cm}$ kadar kazıma işi yapabilmektedir. 95 BG gücündeki traktörlerle $2 \mathrm{~cm}$ kadar kazıma işi yapabilmektedir. 140 BG gücündeki traktörlerle $7 \mathrm{~cm}$ kadar kazıma işi yapabilmektedir. 160 BG gücündeki traktörlerle $9 \mathrm{~cm}$ kadar kazıma işi yapabilmektedir.

\section{$3 \mathrm{~km} / \mathrm{h}$ hızda}

$3.5 \mathrm{~m}$ is genişliğinde LKTM; 85 BG gücündeki traktörlerle 2 $\mathrm{cm}$ kadar kazıma işi yapabilmektedir. 95 BG gücündeki traktörlerle $3 \mathrm{~cm}$ kadar kazıma işi yapabilmektedir. 140 BG gücündeki traktörlerle $8 \mathrm{~cm}$ kadar kazıma işi yapabilmektedir. 160 BG gücündeki traktörlerle 1'den 10 $\mathrm{cm}$ 'ye kadar kazıma işi yapabilmektedir.

$4 \mathrm{~m}$ is genișliğinde LKTM; 85 BG gücündeki traktörlerle $1 \mathrm{~cm}$ kadar kazıma işi yapabilmektedir. 95 BG gücündeki traktörlerle $2 \mathrm{~cm}$ kadar kazıma işi yapabilmektedir. 140 BG gücündeki traktörlerle $6 \mathrm{~cm}$ kadar kazıma işi yapabilmektedir. 160 BG gücündeki traktörlerle $8 \mathrm{~cm}$ kadar kazıma işi yapabilmektedir.

$5 \mathrm{~m}$ is genișliğinde LKTM; 85 ve 95 BG gücündeki traktörlerin gücü yetersiz kalmaktadır. 140 BG gücündeki traktörlerle $4 \mathrm{~cm}$ kadar kazıma işi yapabilmektedir. 160 BG gücündeki traktörlerle $5 \mathrm{~cm}$ kadar kazıma işi yapabilmektedir.

$6 \mathrm{~m}$ is genişliğinde LKTM; 85 ve 95 BG gücündeki traktörlerin gücü yetersiz kalmaktadır. $140 \mathrm{BG}$ gücündeki traktörlerle $2 \mathrm{~cm}$ kadar kazıma işi yapabilmektedir. 160 BG gücündeki traktörlerle $3 \mathrm{~cm}$ kadar kazıma işi yapabilmektedir.

\section{$4 \mathrm{~km} / \mathrm{h}$ hızda}

$3.5 \mathrm{~m}$ is genisliğinde LKTM; 85 ve 95 BG gücündeki traktörlerin gücü yetersiz kalmaktadır. 140 BG gücündeki traktörlerle $4 \mathrm{~cm}$ kadar kazıma işi yapabilmektedir. 160 BG gücündeki traktörlerle $5 \mathrm{~cm}$ kadar kazıma işi yapabilmektedir.

$4 \mathrm{~m}$ is genişliğinde LKTM; 85 ve 95 BG gücündeki traktörlerin gücü yetersiz kalmaktadır. 140 BG gücündeki traktörlerle $1 \mathrm{~cm}$ kadar kazıma işi yapabilmektedir. 160 BG gücündeki traktörlerle $2 \mathrm{~cm}$ kadar kazıma işi yapabilmektedir.

$5 \mathrm{~m}$ iş genişliğinde LKTM; 85,95 ve 140 BG gücündeki traktörlerin gücü yetersiz kalmaktadır. 160 BG gücündeki traktörlerle $1 \mathrm{~cm}$ kadar kazıma işi yapabilmektedir.

6 m iș genissliğinde LKTM; 85, 95140 ve 160 BG gücündeki traktörlerin gücü yetersiz kalmaktadır.

\section{$5 \mathrm{~km} / \mathrm{h}$ hızda}

$3.5 \mathrm{~m}$ is genișliğinde LKTM; 85 ve 95 BG gücündeki traktörlerin gücü yetersiz kalmaktadır. 140 BG gücündeki traktörlerle $2 \mathrm{~cm}$ kadar kazıma işi yapabilmektedir. 160 BG gücündeki traktörlerle $3 \mathrm{~cm}$ kadar kazıma işi yapabilmektedir.

$4 \mathrm{~m}$ is genişliğinde LKTM;

85 ve 95 BG gücündeki traktörlerin gücü yetersiz kalmaktadır. 140 BG gücündeki traktörlerle $1 \mathrm{~cm}$ kadar kazıma işi yapabilmektedir. 160 BG gücündeki traktörlerle 2 $\mathrm{cm}$ kadar kazıma işi yapabilmektedir.

$5 \mathrm{~m}$ ve $6 \mathrm{~m}$ is genişliğinde LKTM; 85, 95, 140 ve 160 BG gücündeki traktörlerin gücü yetersiz kalmaktadır.

\section{$6 \mathrm{~km} / \mathrm{h}$ hızda}

$3.5 \mathrm{~m}$ iş genişliğinde LKTM; 85,95 ve $140 \mathrm{BG}$ gücündeki traktörlerin gücü yetersiz kalmaktadır. 160 BG gücündeki traktörlerle $1 \mathrm{~cm}$ kadar kazıma işi yapabilmektedir.

$4 \underline{m, 5 m}$ ve $6 \mathrm{~m}$ is genisliăinde LKTM; $85,95,140$ ve 160 BG gücündeki traktörlerin gücü yetersiz kalmaktadır. 
Bu değerlendirmelere göre aynı traktör gücünde (85 BG ve 95 BG) ve aynı iş genişliğinde LKTM hız artıkça iş derinliği azalmaktadır. Örneğin, 85 BG traktör gücünde ve $3.5 \mathrm{~m}$ iş genişliğinde LKTM; $1 \mathrm{~km} / \mathrm{h}$ hızda $10 \mathrm{~cm}, 2 \mathrm{~km} / \mathrm{h}$ hızda $7 \mathrm{~cm}$ ve $3 \mathrm{~km} / \mathrm{h}$ hızda $2 \mathrm{~cm}$ iş derinliğinde çalışabilmektedir. Ancak 140 BG ve 160 BG traktör güçlerinde ve $3.5 \mathrm{~m}$ iş genişliğinde LKTM iş derinliğinde değişiklikler meydana gelmektedir. 140 BG traktörde 1 . ve $2 . \mathrm{km} / \mathrm{h}^{\prime} \mathrm{da}$ iş derinlikleri değişmemektedir $(10 \mathrm{~cm}), 3 \mathrm{~km} / \mathrm{h}$ hızdan itibaren iş derinliği azalmaktadır. 160 BG traktörde ise 1., 2. ve $3 . \mathrm{km} / \mathrm{h}^{\prime} \mathrm{da}$ iş derinlikleri değişmemektedir $(10 \mathrm{~cm}), 4$ $\mathrm{km} / \mathrm{h}$ 'dan itibaren iş derinliği azalmaktadır.

Aynı iş genişliğine sahip LKTM ile traktör kombinasyonunda, traktör gücü ve hız artıkça iş derinliğinde artış gözlemlenmiştir. Örneğin $3.5 \mathrm{~m}$ iş genişliğinde, $3 \mathrm{~km} / \mathrm{h}$ hızda, 85 BG traktör $2 \mathrm{~cm}, 95$ BG traktör $3 \mathrm{~cm}, 140$ BG traktör $8 \mathrm{~cm}, 160$ BG traktör $10 \mathrm{~cm}$ iş derinliğinde çalışabilmektedir.

Önceki yapılan çalışmalarda İrsel ve Altınbalık (2018) LKTM bıçak eğim ayarının geliştirilmesine yönelik yaptıkları araştırmada, zamandan $\% 80$ ve yakıt \%85 tasarruf sağlanmışlardır. Aynı bıçak eğim açısında 1.3 kat toprak taşınması nedeni ile dönüm başına yaklaşık 10 litre tasarruf sağlamışlardır.

Yürdem ve Önal (2010) farklı iş genişliğine sahip LKTM çalışma sürelerinin belirlenmesinde \%81.8 tahminleme katsayısını hesaplamışlardır. Bu araştırmalarında çalışma süresi ve saatlik maliyetinin (LKTM ve traktör kombinasyonu) bulunması durumunda tarla tesviyesinin toplam maliyetinin hesaplanabileceğini belirtmişlerdir.

Alkan ve Öztekin (2019) en küçük kareler yöntemi kullanarak, arazi tesviyesi için gerekli olan kazı-dolgu hacim planlarının oluşturulması için otomatik hesaplama yöntemi geliştirmişlerdir.

Masoumi ve ark. (2014) LKTM, tesviye sırasında aşırı yüklenmesini önlemek için bıçak derinliğini kontrol edebilen bir yazılım geliştirmişlerdir. Bu sistem, arazi tesviyesinde çalışma verimliliğini \%19.7 arttırmış ve yakıt tüketimini \%18.4 azaltmıştır.

Zhang ve Noguchi (2017) arazi tesviyesinde iş verimliliğini artırmak ve çalışma süresini azaltmak amacı ile çok robotlu bir traktör sistemi geliştirmişlerdir. Geliştirdikleri sistemde alan büyüklüğünün artmasına bağlı olarak iş verimliliği de artmaktadır.

Omar ve ark., (2018) tesviye endeksi yüzdesini elde etmek ve arazi tesviye haritasını geliştirmek için araştırma yapmışlardır. Bu yöntem ile kesme ve dolgu işleminin daha iyi yapılabileceğini belirtmişlerdir.

Bansal ve ark. (2014) LKTM'nin lazer alıcısı, lazer vericisi ve kontrol kutusunu, mikrodenetleyici sistemini de içeren bir prototip geliştirmişlerdir. Geliştirdikleri prototip, düşük maliyetli olduğu için yüksek maliyetli sistemlere alternatif oluşturabileceklerini belirtmişlerdir.

\section{SONUÇ}

Farklı iş genişliğindeki LKTM'lerinin küremek için ihtiyaç duydukları güç büyüklüklerinin belirlenmesinde toprak özellikleri, kürek yüksekliği, patinaj oranı vb. aynı kalmak koşuluyla hız, iş derinliği ve iş genişliğine bağlı olarak farklı güçteki traktörlere ihtiyaç duyulmaktadır.

İş genişlikleri (LKTM) ve hız artıkça ihtiyaç duyulan traktör gücünde de artış görülmektedir. Aynı iş genişliğine sahip LKTM ile traktör kombinasyonunda, traktör gücü ve hızı artıkça iş derinliğinde de artış gözlemlenmiştir.

Bu kapsamda LKTM'sini kullanan operatörler, hazırlanacak abaklar yardımıyla eğitilmelidir. Bu çalışma ile geliştirilen abaklar, tarla koşullarında denenmelidir. Bu çalışma göstermiştir ki, ülkemizde satılan farklı traktör güçleri ve farklı iş genişliğindeki LKTM kombinasyonlarına göre güç isteklerinin belirlenmesi ile çalışabilecekleri maksimum iş derinliklerinin hesaplanması gerekmektedir.

\section{KAYNAKLAR}

Alkan M, Öztekin T (2019) A Research on the Usage of Least Squares Land Grading Design Method in Microsoft Excel. Journal of Agricultural Faculty of Gaziosmanpasa University, 36 (1): 1-9.

Anonim (2010a) Lazerli Tesviye Makinası LTSV. http://www.ilgitarim.com/tr/urunler/3/tesviye, Erişim tarihi: 26.10.2009.

Anonim (2010b) New Holland TDD serisi. http://www.newholland.com.tr/Portals/1/Products/T ractors/Yerli/TDD_Serisi/Brosur/tdd_broşür_güncel.p df, Erişim tarihi: 26.10 .2009 .

Anonim (2010c) New Holland T6000 serisi. http://www.newholland.com.tr/Portals/1/Products/T ractors/Ithal/T6000_Serisi/Brosur/T6000_26.03.09.pd f, Erişim tarihi: 26.10.2009.

Anonim (2020) Laser Land Leveling System AG308: Operating Manual of Laser Land Leveling System AG308.

http://spoton.net/images/Manual\%20AG308.P\%2001 -10.pdf, Erişim tarihi:09.05.2020

Bansal C, Singh G, Jain DK, Kaur M (2014) Laser land leveling prototype development. International Journal of Latest Research in Science and Technology, 3(6): 130-134.

Erdoğan D, Çolak A, Acar AM (2001) Meliorasyon Makinaları. Ankara Üniversitesi Ziraat Fakültesi Yayın No:1519, Ankara.

İrsel G, Altinbalik MT (2018) Adaptation of tilt adjustment and tracking force automation system on a lasercontrolled land leveling machine. Computers and Electronics in Agriculture 150: 374-386.

Jat ML, Chandna P, Gupta R, Sharma SK, Gill MA (2006) Laser Land Leveling: A Precursor Technology for Resource Conservation. Rice-Wheat Consortium Technical Bulletin Series 7.

Kumaran GS, Rathinakumari AC (2016) Innovations and Interventions in Horticultural Mechanization. Conference on Innovations in Agricultural Mechanization-Development of Linkage Among R\&D Institutes - Industry - Farmers, July 7-8, 86-98, India.

Masoumi AA, Shafaei SM, Gheisari J, Bayani MR (2014) Design, Development and Evaluation of a DepthController for Laser Land-Leveling. ISHS Acta 
Horticulturae 1054: International Conference on Agricultural Engineering: New Technologies for Sustainable Agricultural Production and Food Security.

Omar MFZ, Sharu EH, Isa MM, Mohamad Ghazali MSS, Khadzir MK, Lium PL, Seng CC, Abdullah A (2018) Rice field land preparation through levelling index method. National Conference on Agricultural and Food Mechanization 2018 (NCAFM 2018), 32-34, 17-19 April, Malaysian.

Rajput TBS (2016) Innovations in Water Saving Technologies. Conference on Innovations in Agricultural Mechanization-Development of Linkage Among R\&D Institutes - Industry - Farmers, July 7-8, 260-264, India.

Ravindra Y, Balakrishnan P, Satishkumar U, Kanannavar PS, Halepyati AS, Jat ML, Rajesh NL (2017) Land Levelling and Its Temporal Variability under Different Levelling, Cultivation Practices and Irrigation Methods for
AKGÜL HN Paddy. International Journal of Current Microbiology and Applied Sciences, 6(9): 3784-3789.

Rickman JF (2002) Manual for Laser Land Levelling: National Agricultural Technology Project. Indian Council of Agricultural Research. Rice-Wheat Consortium for the Indo-Gangetic Plains. Rice-Wheat Consortium Technical Bulletin Series 5 .

Tepeli E, Sarıtaş H (2005) Sulama. Tarım ve Köyişleri Bakanlığı Teşkilatlanma ve Destekleme Genel Müdürlüğü Çiftçi Eğitim ve Yayım Serisi, Yayın seri no:42, Ankara.

Yürdem H, Önal i (2010) Prediction of the working time Requirement and field capacity of laser controlled land leveling machines. Tarım Makinaları Dergisi 6(1):19-28.

Zhang C, Noguchi N (2017) Development of a multi-robot tractor system for agriculture field work a college of Mechanical and electronic engineering. Computers and Electronics in Agriculture, 142: 79-90. 
